\title{
Science Epistemological Beliefs from the Perspective of Culture and Gender in Co-Educational Secondary Schools, Kenya
}

\author{
Richard Owino Ongowo \\ Department of Curriculum Instruction and Media, Rongo University, Kitere Hills, Kenya \\ Email: ongoworichard@gmail.com,r_owino@yahoo.com
}

How to cite this paper: Ongowo, R. O. (2020). Science Epistemological Beliefs from the Perspective of Culture and Gender in Co-Educational Secondary Schools, Kenya. Creative Education, 11, 1162-1178. https://doi.org/10.4236/ce.2020.117087

Received: June 29, 2020

Accepted: July 27, 2020

Published: July 30, 2020

Copyright $\odot 2020$ by author(s) and Scientific Research Publishing Inc. This work is licensed under the Creative Commons Attribution International License (CC BY 4.0).

http://creativecommons.org/licenses/by/4.0/

\section{(c) (i) Open Access}

\begin{abstract}
The purpose of the study was to investigate the effects of culture and gender on the development of science epistemological beliefs among co-educational secondary schools in Kisii and Homa-bay counties in Kenya. The study employed a causal comparative design with purposive sampling technique. A 26-item questionnaire called Science Epistemological Beliefs Questionnaire (SEBQ) developed by Conley et al. (2004) was used. The instrument assesses four dimensions of Epistemological Beliefs as Source, Certainty, Development and Justification of scientific knowledge. It was administered to 410 students (Kisii-Abagusii, $\mathrm{n}=207$; Homabay-Luo, $\mathrm{n}=203$ ). The data were analyzed by culture and gender using independent sample t-tests. The findings indicate statistically significant cultural differences in favor of the Abagusii students for three dimensions (Source, Certainty and Development) and statistically significant difference in favor of the Luo students for the dimension of Justification. The findings also indicate non-significant gender differences for the dimensions Source, Certainty and Justification. On the other hand there were statistically significant gender differences in favor of the boys for the dimension of development. Discussions, conclusions and implications are herein made.
\end{abstract}

\section{Keywords}

Science Epistemological Beliefs, Ethnicity, Gender,

Co-Educational Secondary Schools

\section{Introduction}

In a century where great premium is placed on knowledge transfer to novel situations, many educational researchers have given much attention to students' 
epistemological beliefs (Ananiadou \& Claro, 2009; Sadi \& Dagyar, 2015; Peffer \& Ramezani, 2019). Epistemology is a branch of philosophy that is concerned with the nature, origin, limits and validation of human knowledge (Ricco, Pierce, \& Medinilla, 2010; Barvarz, Nami, \& Ahmadi, 2014; Mohamed \& El-Habbal, 2013). Epistemological beliefs refer to an individual's underlying beliefs about the nature of knowledge, knowledge acquisition and limits of knowledge (Perry, 1970; Mohamed \& El-Habbal, 2013). According to Hofer and Pintrich (1997), epistemological beliefs are beliefs about the nature of knowledge, knowledge acquisition and knowing. Schommer (1990) defined epistemological beliefs as individual's subjective beliefs of the definition of knowledge and the way in which the process of acquiring knowledge takes place. Implicit in these definitions is the fact that epistemological beliefs determine how knowledge is acquired by learners and whether that knowledge will be transferable to novel situations.

According to Lodewyk (2007) the early theories of personal epistemology characterized the concept as relatively one-dimensional having a rather uniform developmental trajectory. Perry (1970) argued that students who enter a college perceive knowledge to be simple, certain and provided by an instructor. However as they leave, the same students hold more sophisticated beliefs, viewing knowledge as complex, tentative and derived from a logical and empirical process. Kuhn, Cheney, \& Weinstock (2000) distinguished three developmental stages of epistemological beliefs as absolutism (recognition of knowledge as certain and absolute), multiplism (cognizance of knowledge as uncertain and subjective) and evaluatism (acknowledgement of both uncertainty of knowledge and significance of evaluating knowledge claims). Chandler et al. (cited in Hofer, 2008) recognized an additional stage earlier than absolutism referred to as naïve realism among very young children in which their own perception of knowing is the only view accessible to them. Arslantas (2016), citing the findings of a 5-year longitudinal study by Magolda (1992) on epistemological beliefs explicates four dimensions of epistemological beliefs as absolute, transitional, independent and commitment. Ricco, Pierce, \& Medinilla (2010) observe that the stage based model of personal epistemology indicates that a movement from an objectivist and absolutist epistemology to a more subjectivist and relativist stance of epistemology can occur during pre-adolescence and even middle childhood. In this theoretical positioning, Chan and Elliot (2004) have opined that an individuals' belief system comprises clusters of beliefs interacting with one another and influencing one's decision making, attitudes and actions. Lodewyk (2007) holds that a general theme in epistemological theory is that students develop from a position where knowledge is perceived as right or wrong to a position of relativism and then to a position in which individuals are active constructors of meaning. This perspective recognizes epistemological beliefs as existing in a continuum. However, recent theories have emphasized the multidimensionality and variable developmental path of the construct (Lodewyk, 2007). This implies that epistemological beliefs constitute a sub-system within one's belief system and are considered to have multiple dimensions. Schommer (1990) explained epistemo- 
logical beliefs with a model of five dimensions which included Stability (tentative to unchanging), Structure (isolated to integrity), Source (authority to observation and reason), Speed of acquisition (quick or gradual), Control of acquisition (fixed at birth or lifelong improvement). Many other models have arisen from Schommer's dimensions. This study proceeds in the philosophical trajectory that these beliefs have multiple dimensions and develop in asynchronous fashion.

Much attention has been directed at studying the relationships between epistemological beliefs and self-regulated learning strategies (Savoji, Niusha, \& Boreiri, 2013), Achievement motivation (Ricco, Pierce, \& Medinilla, 2010), Academic achievement (Mohamed \& El-Habbal, 2013; Barvarz, Nami, \& Ahmadi, 2014; Arslantas, 2016). On the other hand, these beliefs have implications for learning, cognitive processing, conceptual change, strategy use and pedagogy (Hofer \& Pintrich, 2002; Hofer, 2008; Chan \& Elliot, 2004; Arslantas, 2016; Berding, Rolf-Wittlake, \& Buschenlange, 2017).

Hofer (2008) observed that research across cultures on epistemological beliefs could help to advance an understanding of the epistemological development trajectory across cultures. These conceptions of epistemological beliefs imply that they are evolutionary and dynamic in nature, implying that individuals' belief about the nature of knowledge and how it is constructed keeps changing. This consequently implies that epistemological beliefs held by individuals affect how they learn and the strategies which they adopt to learn. Culture could also be the lens through which an understanding of epistemological beliefs is expanded. Chen and Pajares (2010) have opined that although much research has been done examining gender differences in epistemological beliefs, some have found significant differences. Chen and Pajares (2010) continue to aver that gender may play an important role in epistemological reasoning in ways that are undetectable.

\subsection{Literature Review}

Karabenick and Moosa (2005) investigated science epistemological beliefs from the perspective of gender and culture among Omani and US college students. The findings indicated that the Omani more than US students believed that knowledge in the sciences was simpler, more certain and accepted scientific authorities as the basis of scientific truth. On the other hand, Omani men were more accepting of authorities than women but the US students exhibited no gender differences. A study by Conley et al. (2004) revealed that students became more sophisticated in their beliefs about source and certainty of knowledge over time but there were no reliable changes in development and justification. There were also no ethnic and gender differences in epistemological beliefs. In a study Lodewyk (2007) examined students' epistemological beliefs according to gender, school orientation, overall academic achievement and performance on two differently structured academic tasks. The findings indicated that belief in simple knowledge significantly predicted overall performance and reflective judgment scores on the ill structured tasks but not on the well-structured tasks. Peer 
(2005) investigated Singaporean students' epistemological beliefs from the perspective of gender using epistemological beliefs questionnaire by Conley et al. (2004). The findings indicated that the mean scores of the female students in all the four subscales were slightly higher than boys' though the differences were not statistically significant. Cano (2005) analyzed changes in epistemological beliefs of boys and girls in secondary schools as they progressed through their studies using Schommer's epistemological beliefs questionnaire. The findings indicated that the boys' beliefs in "quick learning" are more unstable throughout secondary education than girls. The beliefs in "simple knowledge" and "certain knowledge" however followed a similar pattern of development. Marzooghi, Fouladehang and Shemshiri (2008) carried out a study to investigate gender differences in epistemological beliefs using epistemological beliefs questionnaire. The results showed males had naïve epistemological beliefs than females. The girls were higher than boys in terms of their thinking about nature of learning, source of knowledge or the structure of knowledge. Yenice (2015) investigated epistemological beliefs of Turkey students using Schommer's scale which was adapted into Turkish language. The findings indicated that gender does not have a significant effect on the factor "Belief in Learning based on attempt" and the factor "Belief of there is one truth". However, the variable gender was found to have a significant effect on the factor "Belief on learning based on ability". Arslantas (2016) found out no gender differences on teachers candidates' epistemological beliefs on any of the scales of the measure. There were statistically significant relationship between teacher candidates' grade point average and the sub-scale of learning being dependent on talent.

Zhu, Valcke, \& Schellens (2008) carried out a study to investigate cultural differences in epistemological beliefs using Schommer's epistemological beliefs questionnaire. The findings indicated cultural differences between Chinese and Flemish students in terms of "source of knowledge" and "ability to learn" on the other hand, there were similarities in terms of belief of "certain knowledge" and "fixed ability". Filoteo, Talisayon, \& Ferido (2014) carried out a study to find out cultural/ethnic differences between Chavacanos, Tausugs and Visayans from an experimental perspective. Before the enhanced epistemological instructional intervention, there were slight differences in epistemological beliefs however not statistically significant. After the intervention, there were no differences in their epistemological beliefs in Chemistry. Chen and Pajares (2010) investigated ethnic differences in science epistemological among Asian, white students, African American and Hispanic students using the Science epistemological beliefs questionnaire by Conley et al. (2004). The findings indicated that when controlling for previous achievement, the Hispanic students ascribed to more naive beliefs about "certainty" of scientific knowledge compared to their Asian, White and African American peers. Hispanic students and Asian students ascribed to more naive beliefs about "source" of scientific knowledge compared to their African American and White peers. Epistemological beliefs about the "Development" or "Justification" of knowledge were not statistically significant. Tabak and Weins- 
tock (2008) investigated the role that culture plays in the development of epistemological beliefs among the Jews and Bedouins using epistemological reasoning questionnaire that assesses the respondents' absolutist, multiplist or evaluatist positions concerning epistemology. The findings indicated that Bedouins had higher percentages of absolutists than the Jews in all domains. Lin et al. (2013) explored the differences in high school students' science epistemological beliefs and the different relationships between them in Mainland China and Taiwan. The findings indicated that the Taiwanese students generally were more prone to believe that scientific reality is invented, that the development of scientific knowledge is always changing and its status is tentative than the Chinese students were.

The literature reviewed above indicates that studies on epistemological beliefs in relation to culture/ethnicity needs extension to more cultures since differences exist in almost every comparison. The findings on gender based studies are mixed, inconclusive and unequivocal. This implies continuous studies need to be carried out to get a more comprehensive picture of epistemological beliefs from the perspective of gender.

\subsection{Cultural Contexts of the Study}

According to Watson, Ho, \& Raman (1994) culture is the beliefs, values, systems, norms, mores, myths and structural elements of a given organization, tribe or society. They continue to observe that culture exists at national, regional and at corporate levels. Klassen (2004) has observed that a more individualistic culture may be more optimistic in predicting their ability or performance whereas people from a more collectivist cultures may be more realistic in predicting their ability or performance. In the Abagusii culture, men are allowed to be polygamous and exercise control and authority over the rest of the family members. The men have exclusive rights over the control of land, property. The norms and the customs of the Abagusii advantage men in the society and at the same time it encourages social cohesion (Ndeda, 2019). The Luo culture on the other hand, has closely linked economic and social systems that continue to evolve as they migrate. The Luo also practiced polygamy that was a desirable index of a man's worth and an indication of a man's wealth and enhanced his economic and political status. For a woman, life was characterized by competition with co-wives (Ndeda, 2019). Ndeda continues to opine that women control their households where they plant the concept collective ownership and antagonism against the other households. In this scenario, wives become rivals in the possession of property and competition for household favor which promotes self-pride in the women. Division of labour was based on gender and age, however despite this, there was evidence of equality between the genders with regard to their daily work. Using the Hofstede lens to analyze these cultural orientations, it appears that the Abagusii culture enhances a high power distance whereas the Luo culture enhanced High individualism (Hofstede, 1980). 


\subsection{The Present Study}

Studies on epistemological beliefs have dominated the many parts of the world due to its significance in the process of learning and because there is a relationship between beliefs held by learners and the learning competencies. Bodies of literature are progressively indicating that some of the antecedents of the development of epistemological beliefs are culture and gender. Studies on epistemological beliefs are rare in Africa and Kenya to be specific. In the face of the Kenyan government adopting a competency based curriculum, which gives premium to the development of competencies, it is significant to investigate the epistemological beliefs of learners in Kenya from the perspective of culture and gender for three reasons; first, epistemological beliefs are pre-determinants and determinants of learning and learning competencies. Secondly, it would also be significant to do this from the perspective of culture since learning and beliefs about knowledge takes place within a cultural context. Thirdly, since a number of secondary schools in Kenya are co-educational, it would also be important to do this study with the lens of gender to circumvent gender from confounding the interpretation of the findings. The purpose of this study is therefore to investigate how culture, and gender influence the development of Science epistemological beliefs among co-educational secondary school students in Kenya.

\subsection{Research Questions}

The study was guided by the following questions:-

1) Are there cultural differences in Science Epistemological Beliefs of Abagusii students and Luo students?

2) Are there Gender differences in Science Epistemological Beliefs among the students in the co-educational secondary schools?

\subsection{Theoretical Framework}

This study was underpinned by theory of Conley et al. (2004) on the multidimensionality of epistemological beliefs. They theorized epistemological beliefs to fall in four dimensions of source, certainty, development and justification. These dimensions represent two general areas that are at the core of individual epistemological theories that is, beliefs about the nature of knowing and beliefs about the nature of knowledge. The source and justification dimensions reflect beliefs about the nature of knowing where as the certainty and development dimensions are concerned with the nature of knowledge. In this study, epistemological beliefs were determined in the domain of science using Science Epistemological Beliefs Questionnaire (SEBQ).

\section{Methodology}

This section presents the research design that was adopted for the study, the sample of the study, instrumentation and methods of data analysis. 


\subsection{Research Design}

The study adopted a causal-comparative design. Causal-comparative research does not involve control of variables because their effects have occurred or they have fixed manipulative and uninfluenceable properties (Mugenda \& Mugenda, 2003; Gall, Borg, \& Gall, 2003). Causal comparative research attempts to enquire the cause and effect connection for pre-existing differences in groups of individuals (Fraenkel \& Wallen, 2008). The researcher therefore examined the effects of culture and gender (independent variables) on the development of science epistemological beliefs (dependent variables). The consequences in the groups had already occurred hence the independent variables were not manipulated. The groups were compared in order to investigate if there were significant differences in science epistemological beliefs. The possible reasons for the differences in culture and gender were also given (Gall, Borg, \& Gall, 2003).

\subsection{Sampling Procedures and Sample Size}

Two schools that had the needed attributes were purposively sampled for the study. Purposive sampling technique is suitable where attributes of the population are familiar or information rich with respect to the purpose of the study (Mugenda \& Mugenda, 2003; Gall, Borg, \& Gall, 2003; Fraenkel \& Wallen, 2008). Kisii County is dominated by the Abagusii community and Homabay County is dominated by the Luo community, hence had the required respondents for the study. In this study, two pre-existing samples of students from Kisii County and Homabay County co-educational schools were selected in the pursuit of investigating and determining their science epistemological beliefs. Sampling was cautiously done to ensure that the schools with the characteristics of culture and gender parity in enrolment are included in the study. One school was sampled from Homabay County and another one from Kisii County. The sample for this study was 410 students. Table 1 gives the details of sample characteristics.

\subsection{Instrumentation}

The science epistemological beliefs were measured using Science Epistemological Beliefs Questionnaire (SEBQ). This instrument was developed by Conley et al. (2004) to measure science epistemological beliefs. The instrument is a 26-Item questionnaire with 4 subscales as source (5 items), certainty (6 items), development (6 items) and justification (9 items). The items were rated on a 5-point Likert scale $(1=$ Strongly Disagree, $5=$ Strongly Agree $)$. The instrument had an overall reliability of 0.73 . A level of reliability of 0.7 and above is considered appropriate and acceptable for studies (Ogunniyi, 1992; Gall, Borg, \& Gall, 2003). The items for the source and certainty scales were reversed, consequently, scoring was reversed to reflect this. The instrument was administered to students in the two schools and in all the grades by the researcher assisted by the science teachers in the sampled schools. The administration of the instrument took 30 minutes. The data collection process took place in second term of the Kenyan school calendar. The scales and their descriptions are shown in Table 2. 
Table 1. Sample characteristics by grade, gender and ethnicity.

\begin{tabular}{ccccc}
\hline Grade & Gender & Kisii & Homabay & Total \\
\hline \multirow{2}{*}{9} & Female & 27 & 30 & 57 \\
& Male & 29 & 26 & 55 \\
\hline \multirow{2}{*}{10} & Female & 27 & 24 & 51 \\
& Male & 26 & 28 & 54 \\
\hline \multirow{2}{*}{11} & Female & 26 & 25 & 51 \\
& Male & 27 & 27 & 54 \\
\hline \multirow{2}{*}{12} & Female & 25 & 24 & 49 \\
& Male & 20 & 19 & 39 \\
\hline
\end{tabular}

Table 2. Science epistemological beliefs scales and their descriptions.

\begin{tabular}{|c|c|}
\hline Scales & Descriptions \\
\hline Source & $\begin{array}{l}\text { Measures beliefs about knowledge residing in external authorities } \\
\text { e.g. everybody has to believe what scientists say. }\end{array}$ \\
\hline Certainty & Refers to a belief in a right answer e.g. scientific knowledge is always true \\
\hline Development & $\begin{array}{l}\text { Concerns beliefs about science as an evolving and changing subject. } \\
\text { e.g. the ideas in science sometimes change. }\end{array}$ \\
\hline Justification & $\begin{array}{l}\text { Related to the role of experiments and how individuals justify knowledge } \\
\text { e.g. ideas in science can come from your own questions and experiments. }\end{array}$ \\
\hline
\end{tabular}

Adopted from Conley et al. (2004).

\subsection{Data Analysis}

The data from SEBQ were analyzed according to the sub-scales of the instrument. Each item in the instrument was worth a minimum of one point and a maximum of 5 points. Hence the minimum mark that a student could score was 26 and a maximum of 130 for all the sub-scales. Descriptive statistics were used to summarize raw data according to the objectives of the study. Inferential statistics were used to analyze quantitative data and test the research hypotheses. The hypotheses were accepted at a significance level of $\alpha=0.05$. To determine the effect of culture and gender on the development of science epistemological beliefs, independent sample t-tests were carried out. The $t$-test is an inferential statistical procedure used to determine whether means of two samples are significantly different (Fraenkel \& Wallen, 2008). The dependent variable (science epistemological beliefs) was data in ratio scale, the groups were mutually exclusive, there were relationships between observations in each group and the independent variables (ethnicity and gender) were two categorical independent groups. In this regard, independent sample t-test was appropriate for this analysis (Gall, Borg, \& Gall, 2003). Data analysis was conducted with the aid of Statistical Package for Social Sciences (SPSS) version 23. 


\section{Results}

The results of the study are presented according to the objectives by first of all presenting descriptive statistics followed by inferential statistics.

\subsection{Cultural Differences in Science Epistemological Beliefs}

To determine the effect of culture on the development of science epistemological beliefs, the descriptive data analysis are first presented followed by t-test data analysis. Table 3 shows the descriptive statistics.

Table 3 indicates that all students had scores above the mid-point of 12.5 for source, 15 for certainty and development and 22.5 for justification. On the other hand, Abagusii students had higher mean scores in all the sub-scales (Source, Certainty and Development) except in the scale of Justification where the Luo students had higher scores. To determine whether these differences were statistically significant, independent sample t-tests were carried out. Table 4 shows the output of Levene's test and independent sample t-test for the various subscales of SEBQ.

To test for the homogeneity of variances of the samples, Levene's test was used. As can be seen from Table 4, the resulting $p$-values were greater than 0.05 showing that the variances of the samples were not statistically significant. Consequently, the t-tests are based on equal variances assumed.

It can be seen from Table 4 that there were statistically significant differences between the Abagusii students and Luo students in favor of Abagusii students in terms of Source of scientific knowledge $[t(408)=4.466, p<0.05]$, Certainty of scientific knowledge $[t(408)=6.461, p<0.05]$, and Development of scientific knowledge $[t(408=2.724, p<0.05)]$ as also evidenced by the mean differences. On the other hand, there were statistically significant differences between the Luo students and Abagusii students in favor of Luo students in terms of justification of scientific knowledge $[t(408)=-3.930, p<0.05]$ as also evidenced by the $p$ value and mean difference. The effect sizes indicate that $43.1 \%$ of the variance in source of scientific knowledge, $60.8 \%$ of variance in certainty of scientific knowledge, $26.6 \%$ of variance in development of scientific knowledge and $38.1 \%$ of variance in justification of scientific knowledge was caused by cultural orientation of the students.

Table 3. Descriptive statistics of SEBQ scores by cultural setting.

\begin{tabular}{ccccc}
\hline Sub-scale & Cultural Setting & Mean & Standard Deviation & Standard Error Mean \\
\hline \multirow{2}{*}{ Source } & Abagusii & 16.8116 & 4.0480 & 0.28136 \\
& Luo & 14.9754 & 4.2755 & 0.30009 \\
\hline \multirow{2}{*}{ Certainty } & Abagusii & 19.2367 & 4.1097 & 0.28565 \\
& Luo & 16.5222 & 4.3954 & 0.30850 \\
Development & Abagusii & 22.3478 & 4.5255 & 0.31145 \\
& Luo & 21.1084 & 4.6881 & 0.32904 \\
\hline \multirow{2}{*}{ Justification } & Abagusii & 33.9758 & 5.1712 & 0.35943 \\
& Luo & 35.9606 & 5.0520 & 0.35458 \\
\hline
\end{tabular}


Table 4. Levene's tests for equality of variances and Independent sample t-tests by culture.

\begin{tabular}{cccccccccc}
\hline & \multicolumn{7}{c}{ Group 1 } & \multicolumn{7}{c}{ Abagusii, Group 2 = Luo } \\
\cline { 2 - 10 } & $\begin{array}{c}\text { Levene's test for } \\
\text { equality of variances }\end{array}$ & \multicolumn{7}{c}{ t-test for equality of means } \\
\hline Sub-scale & $F$ & Sig & $t$ & $D f$ & $p$-value & $M D$ & SED & $E S$ \\
\hline Source & 0.029 & 0.866 & 4.466 & 408 & 0.000 & 1.836 & 0.414 & 0.431 \\
& & & & 405.76 & 0.000 & 1.836 & 0.411 & \\
\hline Certainty & 0.419 & 0.518 & 6.461 & 408 & 0.000 & 2.714 & 0.420 & 0.608 \\
& & & 6.456 & 404.96 & 0.000 & 2.714 & 0.420 & \\
\hline Development & 0.222 & 0.637 & 2.724 & 408 & 0.007 & 1.239 & 0.455 & 0.266 \\
& & & 2.723 & 406.77 & 0.007 & 1.239 & 0.455 & \\
\hline Justification & 0.443 & 0.506 & -3.930 & 408 & 0.000 & -1.984 & 0.505 & -0.381 \\
& & & -3.931 & 407.99 & 0.000 & -1.984 & 0.504 & \\
\hline
\end{tabular}

$p=0.05, \mathrm{MD}=$ Mean Differences, $\mathrm{SED}=$ Standard Error Mean, ES $=$ Effect Size.

\subsection{Gender Differences in Science Epistemological Beliefs}

To establish whether there were gender differences in science epistemological beliefs, descriptive statistics are first presented followed by inferential statistics. Table 5 below shows the descriptive statistics.

Table 5 shows that males had higher scores than females in all the subscales except in the scale of source. However to establish whether these differences are statistically significant, independent sample $t$ test was carried out. Table 6 shows the output of Levene's test and independent sample t-test for the various subscales of SEBQ.

To test for the homogeneity of variances of the samples, Levene's test was used. As can be seen from Table 6, the resulting $p$-values were greater than 0.05 showing that the variances of the samples were not statistically significant. Consequently, the $t$-tests are based on equal variances assumed.

It can be seen from the table that there were no statistically significant gender differences in science epistemological beliefs in terms of source of scientific knowledge $[t(408)=-0.032, p>0.05]$, Certainty of scientific knowledge $[t(408)=1.946$, $p>0.05]$, justification of scientific knowledge $[t(408)=3.660, p>0.05]$. However in the case of development of scientific knowledge, there were statistically significant gender differences in favour of males $[t(408)=0.272, p<0.05]$. This is further corroborated by the effect sizes for source of scientific knowledge $(0.3 \%)$, certainty of scientific knowledge (19.1\%), justification of scientific knowledge (2.6\%) and development of scientific knowledge (35.6\%). The effect sizes indicate small contribution of gender for cases of no statistical significance (source, certainty, and justification) and medium contribution of gender for the case of statistical significance (development). 
Table 5. Descriptive statistics by gender.

\begin{tabular}{ccccc}
\hline Sub-scale & Gender & Mean & Standard Deviation & Standard Error Mean \\
\hline \multirow{2}{*}{ Source } & Males & 15.8955 & 4.04030 & 0.28498 \\
& Females & 15.9091 & 4.46637 & 0.30895 \\
\hline \multirow{2}{*}{ Certainty } & Males & 18.3284 & 4.37283 & 0.30844 \\
& Females & 17.4737 & 4.51392 & 0.31223 \\
\hline \multirow{2}{*}{ Development } & Males & 22.5771 & 4.52607 & 0.31924 \\
& Females & 20.9234 & 4.61955 & 0.33954 \\
\hline \multirow{2}{*}{ Justification } & Males & 35.0299 & 4.96176 & 0.34998 \\
& Females & 34.8900 & 5.43425 & 0.37590 \\
\hline
\end{tabular}

Table 6. Levene's tests for equality of variances and independent sample t-tests by gender.

\begin{tabular}{|c|c|c|c|c|c|c|c|c|}
\hline \multirow[b]{3}{*}{ Sub-scale } & \multicolumn{8}{|c|}{ Group $1=$ Males, Group $2=$ Females } \\
\hline & \multicolumn{2}{|c|}{$\begin{array}{l}\text { Levene's test for } \\
\text { equality of variances }\end{array}$} & \multicolumn{6}{|c|}{ t-test for equality of means } \\
\hline & $F$ & Sig & $t$ & $D f$ & $p$-value & $M D$ & $S E D$ & ES \\
\hline \multirow[t]{2}{*}{ Source } & 2.251 & 0.134 & -0.032 & 408 & 0.974 & -0.0136 & 0.42113 & -0.003 \\
\hline & & & -0.32 & 406.49 & 0.974 & -0.0135 & 0.42031 & \\
\hline \multirow[t]{2}{*}{ Certainty } & 0.466 & 0.505 & 1.946 & 408 & 0.052 & 0.8547 & 0.43916 & 0.191 \\
\hline & & & 1.947 & 407.98 & 0052 & 0.8447 & 0.43889 & \\
\hline \multirow[t]{2}{*}{ Development } & 0.329 & 0.567 & 3.660 & 408 & 0.000 & 1.654 & 0.45187 & 0.356 \\
\hline & & & 3.661 & 407.86 & 0.000 & 1.654 & 0.45169 & \\
\hline \multirow[t]{2}{*}{ Justification } & 1.820 & 0.178 & 0.272 & 408 & 0.786 & 0.1399 & 0.51451 & 0.026 \\
\hline & & & 0.272 & 406.91 & 0.785 & 0.1399 & 0.51360 & \\
\hline
\end{tabular}

$p=0.05, \mathrm{MD}=$ Mean Differences, $\mathrm{SED}=$ Standard Error Mean, ES $=$ Effect Size.

\section{Discussions}

The finding on the effect of "culture" on the development of science epistemological beliefs has indicated statistically significant cultural differences in favour of the Abagusii students for the dimensions source, certainty and justification and statistically significant cultural differences in favour of Luo students for the dimension of development of scientific knowledge. This finding indicates that the Abagusii students had more sophisticated views as regards the source of scientific knowledge as not residing in external authorities (Source). They had more sophisticated views on the fact that a right answer does not exist (Certainty). Finally, they also had more sophisticated views that scientific knowledge evolving and is not static (Development). The Luo students on the other hand hold more sophisticated views on the need to justify scientific knowledge through empirical investigation (Justification). These views could be generally a reflection of the 
learning environments which the students are presently engaged in. There is a likelihood that the learners are exposed to an environment where scientific knowledge is perceived as tentative, evolving or socially constructed. The findings on Kisii students could also reflect an evolving cultural environment in which the learners believe that knowledge does not exist in external authorities, there is no right answer and that knowledge is evolving. This contradicts the Kisii culture which emphasized recognition and respect of external authorities in the past (Ndeda, 2019). The current study confirms the findings in the international scene that indicated cultural differences for instance, Tabak \& Weinstock (2008) who found that Bedouins had higher percentages of absolutist views of knowledge (Certainty) than the Jews in all the domains. Hofer (2007) found out that USA college students were more sophisticated than Japan students in terms of certainty, simplicity, source and justification. Lin et al. (2013) found out that the Taiwanese students generally were more prone to believe that scientific reality is invented, the development of scientific knowledge is always changing and its status is tentative than the Chinese students were. Zhu, Valcke, \& Schelleus (2008) found out that compared to the Flemish students, the Chinese students had a higher tendency to believe to a greater extent in "certain knowledge" and to a lesser extent in "fixed ability to learn". Chen and Pajares (2010) found out that Hispanic students ascribe to more naïve beliefs about certainty of scientific knowledge compared to the Asian, White and African American peers. The Hispanic students and Asian Students ascribed to more naïve beliefs about the source of scientific knowledge compared to their African American and white peers. Karabenick and Moosa (2005) found out that the Omani students more than US students believed knowledge in the sciences was simpler and more certain. The finding of the current study contradicts the findings by other scholars for instance Conley et al. (2004) found no cultural differences in epistemological thinking among Anglo, African American and Latino students on source, certainty, development and justification of scientific knowledge. Filoteo, Talisayon, \& Ferido (2014) who found that students of different cultures do not differ in their epistemological beliefs. The ethnic groups were Chavacano, Tausug and Visayan. The presence of ethnic or cultural differences in this study could be indicative of the heterogeneity and dynamism of cultural experiences and exposure to science learning on the nature of scientific knowledge and nature of knowing science. This could also be indicative of the cultural context influencing science learning.

The finding on the effect of "gender" on the development of epistemological beliefs has indicated that there are no gender differences in terms of source of scientific knowledge, certainty of scientific knowledge and justification of scientific knowledge. On the other hand, there are gender differences in favour of males in terms of development of scientific knowledge. The non-significant gender differences can be explained from the perspective of proximity of characteristics of learning environments. There is a likelihood that gender inclusive pedagogic practices are taking root in the classrooms as a result of the campaign by the 
government of Kenya and non-governmental organizations. The gender difference in terms of the development of scientific knowledge could be viewed from the fact that the dimensions of science epistemological beliefs do not advance in a unilateral or synchronous fashion within people groups. The current study contradicts the findings some of the findings of Karabenick and Moosa (2005) and agrees with some of them. They found that Omani males were more likely than females to believe that knowledge was simple and originated from scientific authorities. In the same study, there were no gender differences among the US students. The current investigation also agrees with some of the findings of Conley et al. (2004) who revealed that boys and girls were not different in terms of their thinking about source of knowledge, certainty of knowledge or development and justification of knowledge. The current study bears some similarities to some studies for instance Peer (2005) who found that the mean scores of the female students were slightly higher than their male counterparts however the differences were not statistically significant in the four dimensions of epistemological beliefs. The current study departs from the following studies: Chen (2012) found that females tended to be more present in fixed/sophisticated group than males. Cano (2005) found that Spanish secondary male students' beliefs about quick learning were more unstable throughout secondary education. Girls in general expressed more realistic and elaborate epistemological beliefs than boys. Marzooghi et al. (2008), found out that males had more naïve epistemological beliefs than females. Kampa et al. (2016) found out that more females were in the sophisticated and slightly sophisticated dimension whereas more males were in the multiplistic and evidence-based dynamic group. Yenice (2015) found out that gender does not have a significant effect on participants' epistemological beliefs about the role of attempt in learning and there being one truth. However, gender significantly affected the participants' epistemological beliefs on the role of ability in learning in favour of boys.

\section{Conclusion and Recommendations}

Based on the findings of the study, the following conclusions are made:

- Culture influences the development of science epistemological beliefs: To a larger extent, there are no gender differences in the development of science epistemological beliefs. To a lesser extent, there are gender differences in some dimensions.

- In terms of practice, the study recommends that teachers create learning environments where students collaboratively construct scientific knowledge. This will bolster the students' ability to develop more sophisticated epistemological beliefs in science associated with ability to explain and apply scientific knowledge to novel situations. This is likely to minimise the observed cultural differences since epistemological beliefs are modifiable through exposure to progressive learning environments that involve the learners (Weinberg, 2014). 
- There is also need to consistently create gender inclusive pedagogic practices in the classroom so as not to handicap either gender's engagement in learning and performance.

In terms of research, the study recommends the following:

- That more within country ethnic based studies on science epistemological beliefs need to be done to build an advanced picture of science epistemological beliefs from the standpoint of culture especially in Kenya which is multi-cultural in nature.

- More studies that relate to gender on this subject need to be carried out to expand and conclusively establish the status of gender with regard to development of science epistemological beliefs. There is also need to do more studies from a mixed method perspective in which the weakness of one method is complemented by another.

\section{Limitations}

The study has the following limitations:

1) Purposive sampling was employed in this study which reduces the generalization of the findings to a wider population;

2) The sample was also limited to co-educational secondary schools within the two counties.

\section{Conflicts of Interest}

The author declares no external sources of funding and also declares no conflict of interest.

\section{References}

Ananiadou, K., \& Claro, M. (2009). 21st Century Skills and Competencies for New Millenium Learners in OECD Countries. OECD Education Working Paper No. 41, Paris: OECD Publishing.

Arslantas, H. A. (2016). Epistemological Beliefs and Academic Achievement. Journal of Education and Training Studies, 4, 215-220. https://doi.org/10.11114/jets.v4i1.1107

Barvarz, R., Nami, Y., \& Ahmadi, S. (2014). The Relationship between the Epistemological Beliefs and Academic Performance. Procedia-Social and Behavioral Sciences, 114, 121-124. https://doi.org/10.1016/j.sbspro.2013.12.670

Berding, F., Rolf-Wittlake, K., \& Buschenlange, J. (2017). Impact of Different Levels of Epistemic Beliefs on Learning Processes and Outcomes in Vocational Education and Training. World Journal of Education, 7, 103-114.

Cano, F. (2005). Epistemological Beliefs and Approaches to Learning: Their Change through Secondary School and Their Influence in Academic Performance. British Journal of Educational Psychology, 75, 203-221. https://doi.org/10.1348/000709904X22683

Chan, K. W., \& Elliot, R. G. (2004). Exploratory Study of Hong Kong Teacher Education Students' Epistemological Beliefs: Cultural Perspectives and Implications on Beliefs Research. Contemporary Educational Psychology, 27, 392-414.

https://doi.org/10.1006/ceps.2001.1102 
Chen, J. A. (2012). Implicit Theories, Epistemic Beliefs and Science Motivation: A Person Centred Approach. Learning and Individual Differences, 22, 724-735. https://doi.org/10.1016/j.lindif.2012.07.013

Chen, J., \& Pajares, F. (2010). Implicit Theories of Ability of Grade 6 Students: Relation to Epistemological Beliefs and Academic Motivation and Achievement in Science. Contemporary Educational Psychology, 35, 75-87. https://scholarworks.wm.edu/articles/49 https://doi.org/10.1016/j.cedpsych.2009.10.003

Conley, A. M., Pintrich, P. R., Vekiri, I., \& Harrison, D. (2004). Changes in Epistemological Beliefs in Elementary Science Students. Contemporary Educational Psychology, 29, 186-204. https://doi.org/10.1016/j.cedpsych.2004.01.004

Filoteo, L. B., Talisayon, V. M., \& Ferido, M. B. (2014). Epistemological Beliefs, Thinking Skills and Concept Understanding in Chemistry. International Journal of Technology and Inclusive Education, 1, 327-381. https://doi.org/10.20533/ijtie.2047.0533.2014.0049

Fraenkel, J. R., \& Wallen, N. E. (2008). How to Design and Evaluate Research in Education (7th ed.). New York: McGraw-Hill.

Gall, M. D., Borg, W. R., \& Gall, J. P. (2003). Educational Research: An Introduction (7th ed.). New York: Longman, Inc.

Hofer, B. K. (2007). Learning Strategies and Epistemic Beliefs: Cultural Influences in Japan and the US. Chicago, IL: The American Educational Research Association.

Hofer, B. K. (2008). Personal Epistemology and Culture. In M. S. Khine (Ed.), Knowing, Knowledge and Beliefs: Epistemological Studies across Cultures (pp. 3-22). Middlebury, VT: Middle Bury College. https://doi.org/10.1007/978-1-4020-6596-5_1

Hofer, B. K., \& Pintrich, P. (1997). The Development of Epistemological Theories: Beliefs about Knowledge and Knowing and Their Relation to Learning. Review of Educational Research, 67, 88-140. https://doi.org/10.3102/00346543067001088

Hofer, B. K., \& Pintrich, P. R. (2002). Personal Epistemology: The Psychology of Beliefs about Knowledge and Knowing. Mahwah, NJ: Lawrence Erlbaum Associates. https://doi.org/10.4324/9781410604316

Hofstede, G. (1980). Culture's Consequences: International Differences in Work Related Values. Beverly Hills, CA: Sage.

Kampa, N., Neumann, I., Heitmann, P., \& Kremer, K. (2016). Epistemological Beliefs in Science-A Person Centred Approach to Investigate High School Students' Profiles. Contemporary Educational Psychology, 46, 81-93. https://doi.org/10.1016/j.cedpsych.2016.04.007

Karabenick, S. A., \& Moosa, S. (2005). Culture and Personal Epistemology: USA and Middle Eastern Students' Beliefs about Scientific Knowledge and Knowing. Social Psychology of Education, 8, 375-393. https://doi.org/10.1007/s11218-005-1826-3

Klassen, R. M. (2004). Optimism and Realism: A Review of Self-Efficacy from across Cultural Perspective. International Journal of Psychology, 39, 205-230. https://doi.org/10.1080/00207590344000330

Kuhn, D., Cheney, R., \& Weinstock, M. (2000). The Development of Epistemological Understanding. Cognitive Development, 15, 309-328. https://doi.org/10.1016/S0885-2014(00)00030-7

Lin, T., Deng, F., Chai, C. S., \& Tsai, C. (2013). High School Students' Scientific Epistemological Beliefs, Motivation in Learning Science and Their Relationships: A Comparative Study within the Chinese Culture. International Journal of Educational Development, 33, 33-47. https://doi.org/10.1016/j.ijedudev.2012.01.007 
Lodewyk, K. R. (2007). Relations among Epistemological Beliefs, Academic Achievement and Task Performance in Secondary School Students. Educational Psychology, 27, 307-327. https://doi.org/10.1080/01443410601104080

Magolda, B. (1992). Students' Epistemologies and Academic Experiences: Implications for Pedagogy. Review of Higher Education, 15, 265-287.

https://doi.org/10.1353/rhe.1992.0013

Marzooghi, R., Fouladehang, M., \& Shemshiri, B. (2008). Gender and Grade Level Differences in Epistemological Beliefs of Iranian Undergraduate Students. Journal of Applied Sciences, 8, 4968-4701. https://doi.org/10.3923/jas.2008.4698.4701

Mohamed, M. T., \& El-Habbal, M. (2013). The Relationship between Epistemic Beliefs and Academic Performance: Are Better Students Always More Mature? Journal of Educational and Developmental Psychology, 3, 158-172. https://doi.org/10.5539/jedp.v3n1p158

Mugenda, O., \& Mugenda, A. (2003). Research Methods Quantitative and Qualitative Approaches. Nairobi: Acts Press.

Ndeda, M. A. J. (2019). Population, Movement, Settlement and the Construction of Society to the East of Lake Victoria in Pre-Colonial Times: The Western Kenya Case. The East African Review, 52, 83-108. http://journals.openedition.org/eastafrica/473

Ogunniyi, B. M. (1992). Understanding Research in Social Science. Nigeria: Ibadan University Press.

Peer, J. (2005). Students' Epistemological Beliefs about Science: The Impact of School Science Experience. Journal of Science and Mathematics in SE Asia, 28, 81-95.

Peffer, M. E., \& Ramazani, N. (2019). Assessing Epistemological Beliefs of Experts and Novices via Practices in Authentic Science Inquiry. International Journal of STEM Education, 6, 1-23. https://doi.org/10.1186/s40594-018-0157-9

Perry, W. (1970). Forms of Intellectual and Ethical Development in the College Years: A scheme. New York: Holt, Rinehart and Winston.

Ricco, R., Pierce, S. S., \& Medinilla, C. (2010). Epistemic Beliefs and Achievement Motivation in Early Adolescence. Journal of Early Adolescence, 30, 305-340. https://doi.org/10.1177/0272431609333299

Sadi, O., \& Dagyar, M. (2015). High School Students' Epistemological Beliefs, Conceptions of Learning and Self-Efficacy for Learning Biology: A Study of Their Structural Models. Eurasia Journal of Mathematics, Science and Technology Education, 11, 1061-1079. https://doi.org/10.12973/eurasia.2015.1375a

Savoji, A. P., Niusha, B., \& Boreiri, L. (2013). Relationship between Epistemological Beliefs, Self-Regulated Strategies and Academic Achievement. Procedia-Social and Behavioral Sciences, 84, 1160-1165. https://doi.org/10.1016/j.sbspro.2013.06.719

Schommer, M. (1990). Effects of Beliefs about the Nature of Knowledge on Comprehension. Journal of Educational Psychology, 82, 498-504. https://doi.org/10.1037/0022-0663.82.3.498

Tabak, I., \& Weinstock, M. (2008). A Socio-Cultural Exploration of Epistemological Beliefs. In M. S. Khine (Ed.), Knowing, Knowledge and Beliefs (pp. 177-195). Dordrecht: Springer. https://doi.org/10.1007/978-1-4020-6596-5_8

Watson, R. T., Ho, T. H., \& Raman, K. S. (1994). Culture: A fourth Dimension of Group Support Systems. Communications of the ACM, 37, 45-55.

https://doi.org/10.1145/194313.194320

Weinberg, F. J. (2014). Knowledge Sharing in Work Teams: A New Model and Research Questions. The Learning Organization, 22, 40-57.

https://doi.org/10.1108/TLO-11-2013-0067 
Yenice, N. (2015). An Analysis of Science Students Teachers' Epistemological Beliefs and Metacognitive Perceptions about the Nature of Science. Educational Sciences: Theory and Practice, 15, 1623-1636.

Zhu, C., Valcke, M., \& Schelleus, T. (2008). The Relationship between Epistemological Beliefs, Learning Conceptions and Approaches to Study: A Cross Cultural Structural Model? Asia Pacific Journal of Education, 28, 411-423.

https://doi.org/10.1080/02188790802468823 